\title{
Smart OBDII Interface Development
}

\author{
Rashid Bin Mohammed Al Soutia ${ }^{a}$, Shaik Asif Hussain ${ }^{\mathrm{a}}$
}

Smart OBDII Interface Development is to create all the information about the vehicle's performance and diagnostic trouble code (DTC) easily available to drivers or technician and mechanism by using an output device such as mobile or any display device in the vehicles. This work solves many problems by providing many useful information for driver like reading the battery voltage in real time. The main objectives are shown below depends on the time given as to complete the project planning and the limitation faced in the process used to implement the system. The project planning objectives produce create a development device can integrate with ELM327 interface module to communicate by data link connector in the vehicles to provide reading the real data from the engine control unit and detect the diagnostic trouble code. To implement support for reading the battery voltage which gives for driver and inspector the very important information needed to avoid the trouble in the car. To protect and help when the vehicle battery breakdown and the vehicle does not run so, can use it as a jump starter and as computer memory savers.

Keywords: Diagnostic Trouble Code (DTC), ELM 327, Jump starter

\section{Introduction}

Today vehicles are very smart in their operation when comparing from earlier years. The old cars controlling the ignition system mechanically so, that operation gives more fuel consumption or more emission because air and fuel mixture not perfect. Smart OBDII interface development comes to helping technicians to detect some minor faults easily without the need for special scanning tools which complex and expensive and also to provide this service for the drivers of vehicles and reduce the cost and shorten the time for them and help those to detect some minor malfunctions without reference to the technical specialist. The idea of the project centered around three main sections: Vehicle diagnoses trouble code read automatically by smart OBDII LEM327 Bluetooth interface Module and display the diagnostic trouble code (DTC) in the android mobile phone or any device working with android operating system by using very famous apps for the diagnostic trouble code called torque pro or display in the vehicle driver LCD. Measuring the vehicle battery voltage and load to display it for a driver or technician to make sure that power in the battery in good condition before any inspection and this information of battery voltage most important for any technical procedures before any inspection.

Used the OBD-II data link port to connect with external battery 12 volt to provide the system by power to give charging for external backup $12 \mathrm{~V}$ battery to use later after reduced the power to $9 \mathrm{~V}$ and use it as computer memory saver can use in conjunction with a jump starter to preserve vehicle codes and electronic presets, seat sitting and radio channel AM/FM sitting while a vehicle battery disconnected. Also this external battery $12 \mathrm{~V}$ connected with dc to de converter to increasing the capacity of power to use as a jumper starter in emergency situation.

\section{Proposed Approach}

This project entitled "Smart OBD-II Interface Development" is based on four main components, the data link connector on the vehicle, LEM327 Bluetooth module, microcontroller and DC to DC voltage convertor. That entire component together creates new system using smart technologies of OBD-II to help drivers and technicians to get the important information freely every time about the engine control unit operation and can be able to reading diagnostic trouble codes (DTC). The previous related project uses those technologies in some application separately.

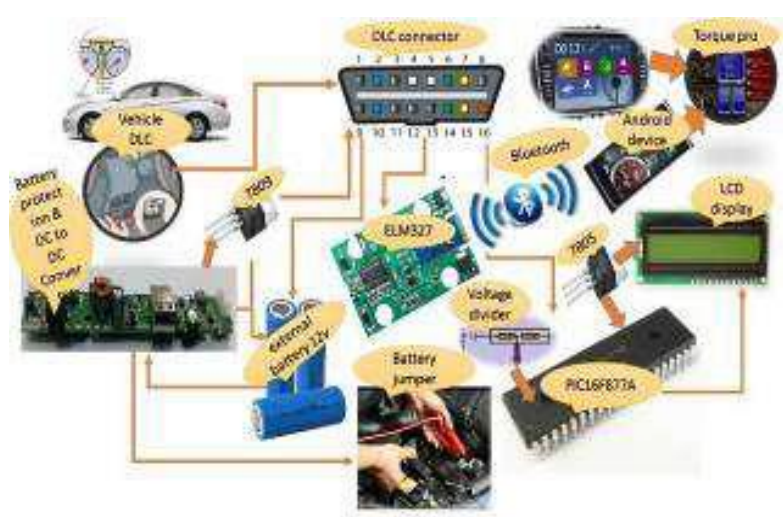

Fig 1.1: Show the interconnected devices

All previous projects used the same technology OBD-II to communicate with the vehicle by the ELM 327 Bluetooth module. So my project differs from others, it focuses on development the interface of the OBD-II to get more use the features of OBD-II pins to reduce the cost of inspection and

a. Department of Electrical Engineering, Middle East College, Muscat, OMAN

Correspondence, shussain@mec.edu.om, 
helps the driver in an emergency situation when the vehicle battery breakdown to run vehicle by any source like as backup battry source. The ELM327 is used for translating the on-board diagnostics OBD interface found on most modern cars.

\section{SYSTEM BLOCK DIAGRAM}

The operation of the system has divided in three main operation processes: The first operation contains two major components in the project, ELM327 Bluetooth interface Module and Data Link Connector. The action starts when connected the ELM327 Bluetooth Interface Module with OBD-II port Data Link Connector in the vehicle and run the engine. The engine control unit sends all information and live data to the ELM327 Bluetooth interface module which used the Bluetooth technology for sharing that useful information for mobile application to display it. The application programmed to read the data live and the Diagnosis trouble code from the engine control unit and provide for users to erase the DTC and gives the drivers warning when fault detected.

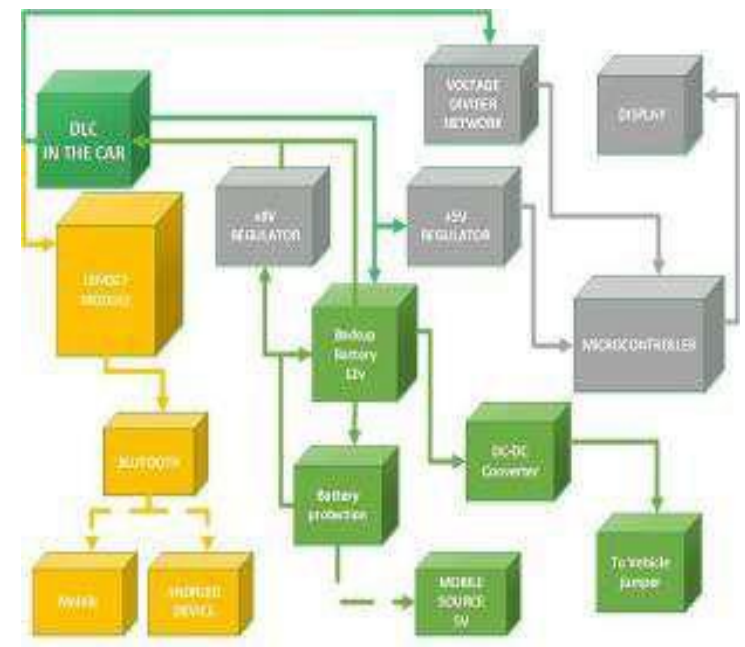

Figure 2: Block details of the process operation

The operation of the system has divided in three main operation processes: The first operation contains two major components in the project, ELM327 Bluetooth interface Module and Data Link Connector. The action starts when connected the ELM327 Bluetooth Interface Module with OBD-II port Data Link Connector in the vehicle and run the engine. The engine control unit sends all information and live data to the ELM327 Bluetooth interface module which used the Bluetooth technology for sharing that useful information for mobile application to display it. The application programmed to read the data live and the Diagnosis trouble code from the engine control unit and provide for users to erase the DTC and gives the drivers warning when fault detected. The second operation, by using PIC Microcontroller to measuring voltage which has inbuilt ADC (Analog to
Digital Converter) to read input voltage value and showing the battery voltage and amp to display by LCD for a driver or technician to make sure the power at the battery before the inspection and this is one of the most important technical procedures before any inspection Third operation, using the OBD-II port to provide the system by power to give charging for external backup $12 \mathrm{~V}$ battery. This battery we can used for many thing.in the project designed system will used the external battery $12 \mathrm{~V}$ as computer memory savers to use in conjunction with a jump starter to preserve vehicle codes and electronic presets like as odometer, seat setting and the radio FM/AM channels while a vehicle battery disconnected so ,in this process the battery $12 \mathrm{~V}$ connected with voltage regulator 7809 to reduce voltage to avoid any risk for the vehicle systems.

\section{SYSTEM IMPLEMENTATION PROTOTYPING}

This battery we can used for many thing.in the project designed system will used the external battery $12 \mathrm{~V}$ as computer memory savers to use in conjunction with a jump starter to preserve vehicle codes and electronic presets like as odometer, seat setting and the radio FM/AM channels while a vehicle battery disconnected so, in this process the battery $12 \mathrm{~V}$ connected with voltage regulator 7809 to reduce voltage to avoid any risk for the vehicle systems.

Table 1: shows the battery voltage details of car

\begin{tabular}{|c|c|c|}
\hline \multicolumn{3}{|c|}{ The battery voltage when engine is running } \\
\hline Battery range & Design value & Simulation value \\
\hline Fully charge & $14.7 \mathrm{~V}$ & $14.6 \mathrm{~V}$ \\
\hline \multicolumn{3}{|c|}{1 - } \\
\multicolumn{3}{|c|}{} \\
\hline Battery range & Design value & Simulation value \\
\hline Fully charged & $12.6 \mathrm{~V}$ & $12.5 \mathrm{~V}$ \\
\hline Half charged & $12.3 \mathrm{~V}$ & $12.2 \mathrm{~V}$ \\
\hline dead & $11.9 \mathrm{~V}$ & $11.8 \mathrm{~V}$ \\
\hline
\end{tabular}

Table 2: Voltage divider bias method for resistors

\begin{tabular}{|c|c|c|}
\hline \multicolumn{3}{|c|}{ comparing the value of voltage across R2 by using voltage divider } \\
method \\
\hline The point & Input voltage Vin & $\begin{array}{c}\text { Simulation value (V Out } \\
\text { across } \mathrm{R} 2)\end{array}$ \\
\hline $\mathbf{1}$ & $12 \mathrm{~V}$ & $+2 \mathrm{~V}$ \\
\hline $\mathbf{2}$ & $12.6 \mathrm{~V}$ & $+2 \mathrm{~V}$ \\
\hline $\mathbf{3}$ & $14.7 \mathrm{~V}$ & $+2.45 \mathrm{~V}$ \\
\hline $\mathbf{4}$ & $30 \mathrm{~V}$ & $+5 \mathrm{~V}$ \\
\hline
\end{tabular}




Table 3: showing testing the vehicle battery
\begin{tabular}{|c|c|c|c|c|}
\hline \multicolumn{5}{|c|}{ testing the vehicle battery monitoring unit } \\
\hline No & The case & $\begin{array}{c}\text { Design } \\
\text { value }\end{array}$ & $\begin{array}{c}\text { By Using } \\
\text { commercial } \\
\text { voltmeter }\end{array}$ & $\begin{array}{c}\text { By using } \\
\text { the project } \\
\text { unit }\end{array}$ \\
\hline $\mathbf{1}$ & $\begin{array}{c}\text { When the } \\
\text { engine is } \\
\text { off }\end{array}$ & $12.6 \mathrm{~V}$ & $12.57 \mathrm{~V}$ & $12.8 \mathrm{~V}$ \\
\hline $\mathbf{2}$ & $\begin{array}{c}\text { When the } \\
\text { engine is } \\
\text { run }\end{array}$ & $14.7 \mathrm{~V}$ & $14.47 \mathrm{~V}$ & $15.9 \mathrm{~V}$ \\
\hline
\end{tabular}

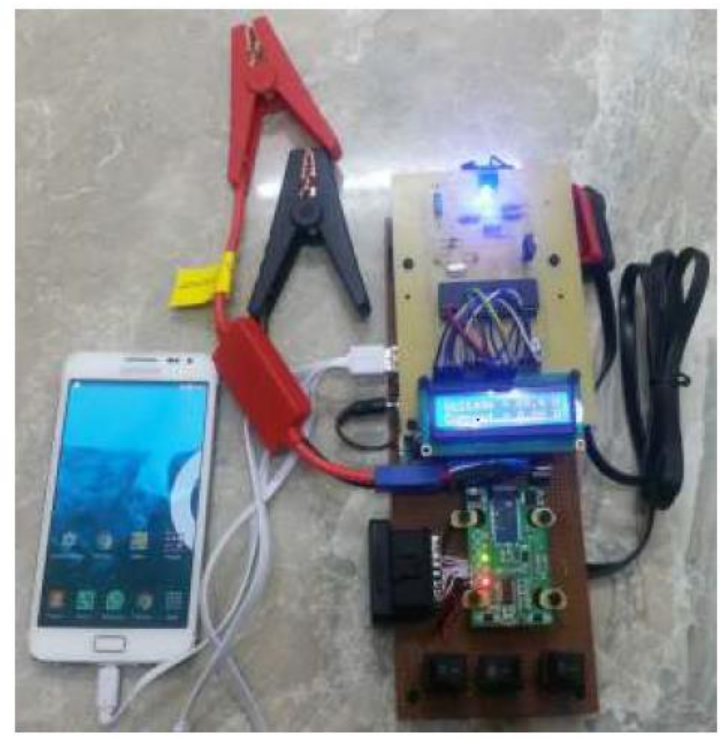

Figure 3: The results of OBDII interface connected for malfunctioning

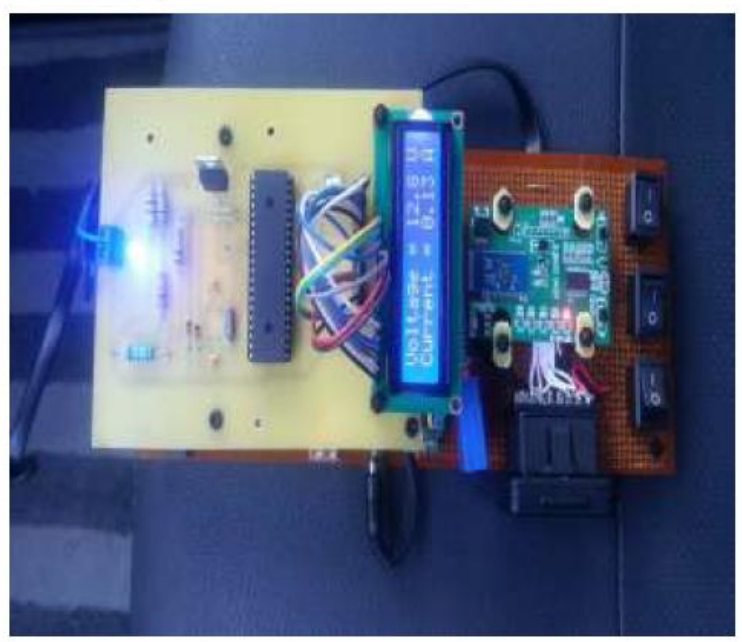

Figure 4: Smart system design interfaced for battery Driving voltage

\section{ACKNOWLEDGMENT}

First of all, I thank ALLAH for giving me the health and the ability to finish this work. Second, I would extend thanks to all Instructors at MEC College Especially Electronics and
Telecommunication Department. Also, my deepest thanks to head department and my project planning supervisor Dr. Shaik Asif Hussain. Finally, I would like to thank my family and friends for putting up with my constant moaning about the project and supporting me through the difficult times.

\section{REFERENCES}

[1] (2015)., I.S.O.(. (August 2015) Road vehicles Communication.

[2] CanOBD2. Innova (2011. Web. 18 Feb) 'OBD2 Diagnostic Operational Modes'.

[3] Davis, L. (1998) 'CAN Bus Interface Description, CAN Bus Pinout'.

[4] Donal (2002) 'An Embedded Automotive Monitoring Device'.

[5] Dzhelekarski, P.a.D.A. (2008) 'Initializing Communication to Vehicle OBDII System'.

[6] Elektor (2005) 'Auto-Diagnose mit OBD-2'.

[7] Elm Electronics (2005) 'ELM 327 OBD to RS232 Interpreter'.

[8] Ferris, D.H..V.G.J.F..W.W.. (May 2015.) 'OBD Presentation for China US/CARB OBD'.

[9] Intel (1995) 'Introduction to the Controller Area Network

(CAN) Protocol'.

[10] Keenan, J. (April, 2009) 'MQP-SJB-4C09 Creating A Wireless OBDII Scanner'.

[11] Microchip (2004) 'MCP2551 High-speed CAN Transceiver'.

[12] Noxon, J. (23 Feb. 2011.) 'Opendiag OBD-II Schematics \& PCB Layout'.

[13] Özen Elektronik (2004) 'EOBD/OBDII to RS232 Gateway'.

[14] 'Proceedings of the Fourteenth Int. Conference

ELECTRONICS'05'.

[15] Valentine, R. (1998) 'Motor Control Electronic Handbook'. 